\title{
GYMNOTHORAX SHAOI, A NEW SPECIES OF MORAY EEL (ANGUILLIFORMES: MURAENIDAE) FROM SOUTHEASTERN TAIWAN
}

\author{
Hong-Ming Chen \\ Department of Aquaculture, National Taiwan Ocean University, Keelung, Taiwan 202, R.O.C., \\ hmchen@mail.ntou.edu.tw \\ Kar-Hoe Loh \\ Department of Aquaculture, National Taiwan Ocean University, Keelung, Taiwan 202, R.O.C.
}

Follow this and additional works at: https://jmstt.ntou.edu.tw/journal

Part of the Aquaculture and Fisheries Commons

\author{
Recommended Citation \\ Chen, Hong-Ming and Loh, Kar-Hoe (2007) "GYMNOTHORAX SHAOI, A NEW SPECIES OF MORAY EEL \\ (ANGUILLIFORMES: MURAENIDAE) FROM SOUTHEASTERN TAIWAN," Journal of Marine Science and Technology. \\ Vol. 15: Iss. 2, Article 2. \\ DOI: $10.51400 / 2709-6998.2035$ \\ Available at: https://jmstt.ntou.edu.tw/journal/vol15/iss2/2 \\ This Research Article is brought to you for free and open access by Journal of Marine Science and Technology. It has been \\ accepted for inclusion in Journal of Marine Science and Technology by an authorized editor of Journal of Marine Science and \\ Technology.
}




\section{GYMNOTHORAX SHAOI, A NEW SPECIES OF MORAY EEL (ANGUILLIFORMES: MURAENIDAE) FROM SOUTHEASTERN TAIWAN}

\section{Acknowledgements}

We wish to thank Dr. Kwang-Tsao Shao, Acting Director of the Research Center for Biodiversity, Academia Sinica; and Dr. Ching-Fong Chang in our University, for their valuable advice and support throughout the studies. We give particular thanks to Dr. Daniel J. Sheehy and Dr. Susan Vik. for revising the manuscript. We are very grateful to Mr. Wung-Jyh Yang and Captain Jiunn-Shiun Chiou who collected the type and relative specimens. Mr. Wei-Jen Chen, Mr. Yen-Chieh Tseng, Mr. Chao-Sen Yang and Miss Shih-Ying Tien measured the type specimens and reared the comparative morays in our aquaria. These studies were originally supported by Fisheries Agency, Council of Agriculture grants "92AS-9.1.1- FA-F1(8);

93AS-9.1.1-FA-F2(1-4); 94AS-9.4.1-FA-F1 (3-4)" to Hong-Ming Chen. This study was also partially supported by the Center for Marine Bioscience and Biotechnology in National Taiwan Ocean University. 


\title{
GYMNOTHORAX SHAOI, A NEW SPECIES OF MORAY EEL (ANGUILLIFORMES: MURAENIDAE) FROM SOUTHEASTERN TAIWAN
}

\author{
Hong-Ming Chen* and Kar-Hoe Loh*
}

Key words: new species, Muraenidae, moray eel, Gymnothorax shaoi.

\begin{abstract}
A new species of moray eel, Gymnothorax shaoi, is described here based on ten specimens collected in southeastern Taiwan. The new muraenid is distinct from its most similar species, Gymnothorax fimbriatus, in the character combinations of having brown body color, dark brown spots in at least three rows on body side and spots on posterior dorsal and caudal fin not forming oblique streaks; paler rictus, jaws, and inner mouth; fins without pale margins; no bend in lower jaw; fewer total vertebrae; and smaller in maximum body size. G. shaoi's eyes have yellow to orange irises, body with dark reddish brown spots, and no yellow mucus on the top of head when alive. $G$. shaoi also differs from another similar species, G. reevesii, in several characteristics: smaller body depth, longer snout length, absence of pale posterior nostrils, with a few dark brown dots on the dorsal fin, no blackish margins on fins, and has more inner maxillary and inner dentary teeth.
\end{abstract}

\section{INTRODUCTION}

During 2001-2003 in a series of projects entitled "Investigations and studies of endangered muraenid fishes from the waters around Taiwan", we collected many specimens of moray eels from the waters surrounding Taiwan. Among these, we noted some exceptional specimens that had a color pattern similar to but distinct from Gymnothorax fimbriatus (Bennett, 1832) [1]. In June 2003, a live specimen with variable patterned "G. fimbriatus" was obtained from Chengkung in southeastern Taiwan. It was transported to our laboratory in the Department of Aquaculture at National Taiwan Ocean University, and maintained alive to observe its behavior and morphological characters in detail. We found that this specimen was quite different from $G$. fimbriatus and could be an undescribed species. In August 2003, a fishing shop

Paper Submitted 03/27/06, Accepted 09/15/06. Author for Correspondence: Hong-Ming Chen. E-mail: hmchen@mail.ntou.edu.tw.

*Department of Aquaculture, National Taiwan Ocean University, Keelung, Taiwan 202, R.O.C. master, Mr. Wung-Jyh Yang, provided 8 additional specimens of this Gymnothorax sp. from Chengkung. In August 2005, Captain Jiunn-Shiun Chiou provided another live specimen of this species from Changbin in southeastern Taiwan. It was kept alive and recorded in detail as well in our laboratory for more than 4 months. After examination of these specimens and make the comparison on their morphology to other similar moray species, we propose and describe it here as a new species.

\section{MATERIALS AND METHODS}

The methods of measurement followed those of Chen et al. [8] or Böhlke and Randall [5]. Proportional measurements of type specimens of the new moray were expressed as percentage of the total length (TL) or the head length (HL). Preanal length (PAL) was measured from the snout tip to the mid-anus; body depth was measured at the gill openings (DGO) and at the anus (DA) that did not include the fins; snout length was measured from snout tip to the anterior margin of the eye; upper jaw length was from snout tip to mouth angle; and lower jaw length was from lower jaw tip to mouth angle. Counts for the vertebral formula were obtained from radiographs, as explained in Böhlke [3] and Chen et al. [9]; the mean vertebral formula (MVF) provided mean values for predorsalpreanal-total vertebrae counts. Teeth counts referenced Hatooka [11], were approximate, and included sockets of missing teeth. Gonadal type was determined by gross and histological examination of the muraenid gonad.

The type specimens were stored in the Museum of the Research Center for Biodiversity, Academia Sinica (ASIZP), and in the collections of the Laboratory of Aquatic Ecology, Department of Aquaculture, National Taiwan Ocean University (TOU-AE). The related muraenid specimens that we examined were also from National Museum of Marine Science \& Technology (NMMSTP) and Fisheries Research Institute (FRI). 


\section{RESULTS AND DISCUSSION}

Gymnothorax shaoi n. sp.

(Chinese name: 邵氏裸胸魹; Shao's Rou-hsun-tsung)

(English name: Shao's moray eel)

(Figures 1, 2, 3 a, 4; Table 1)

Holotype: ASIZP0062978 (Figure 1), male, 567 $\mathrm{mm}$ TL, off shore of Sanshengtai $\left(23.130^{\circ} \mathrm{N}, 121.414^{\circ} \mathrm{E}\right)$, Chengkung, Taitung, longline, Wung-Jyh Yang, 19 Aug. 2003.

Paratypes: ASIZP0062979-80, 2 specimens, females, 401-457 mm TL, off shore of Sanshengtai, longline, Wung-Jyh Yang, 19 Aug. 2003; TOU-AE0370, 0371, 0373, 0375, 4 specimens, males, 398-608 mm TL, and TOU-AE0372, female, $405 \mathrm{~mm} \mathrm{TL}$, off shore of Sanshengtai, longline, Wung-Jyh Yang, 19 Aug. 2003; TOU-AE0381(Figure 3a), female, $379 \mathrm{~mm} \mathrm{TL}$, tidal pool of Hsiaogang $\left(23.156^{\circ} \mathrm{N}, 121.405^{\circ} \mathrm{E}\right)$, Chengkung, Taitung, clove oil, Kar-Hoe Loh, 22 Jun. 2003; TOUAE1797(Figure 4), female, $492 \mathrm{~mm} \mathrm{TL}$, off shore of Changbin $\left(23.311^{\circ} \mathrm{N}, 121.453^{\circ} \mathrm{E}\right)$, Taitung, longline, Captain Jiunn-Shiun Chiou, 1 Aug. 2005.

\section{Comparative materials:}

Gymnothorax fimbriatus: 77 specimens. ASIZP0056652, 2: 171-195 mm; NMMSTP00216, 121 mm; FRIP20092, $610 \mathrm{~mm}$; TOU-AE0211, $764 \mathrm{~mm}$; TOU-AE0218, 633 mm; TOU-AE0288, 488 mm; TOUAE0289, $423 \mathrm{~mm}$; TOU-AE0391, $337 \mathrm{~mm}$; TOUAE0392, $305 \mathrm{~mm}$; TOU-AE0504, $113 \mathrm{~mm}$; TOUAE0505, $246 \mathrm{~mm}$; TOU-AE0506, $285 \mathrm{~mm}$; TOUAE0530, 599 mm; TOU-AE0569, 340 mm; TOU-

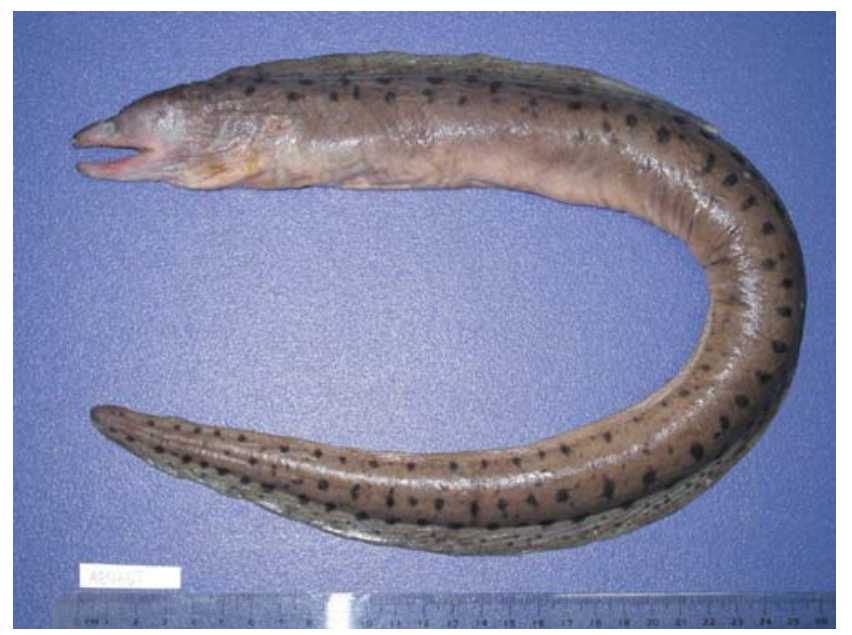

Fig. 1. Holotype of Gymnothorax shaoi n. sp., male, ASIZP 0062978, $567 \mathrm{~mm}$ TL, Chengkung, Taitung, longline.
AE0631-0637, 7: 332-842 mm; TOU-AE0650-0651, 2: 224-351 mm; TOU-AE0654-0656, 3: 246-694 mm; TOU-AE0727-0734, 8: 351-770 mm; TOU-AE0802, $497 \mathrm{~mm}$; TOU-AE0808, $395 \mathrm{~mm}$; TOU-AE0811-0813, 3: 333-652 mm; TOU-AE0921, $416 \mathrm{~mm}$; TOU-AE0931, 405 mm; TOU-AE0936-0937, 2: 427-605 mm; TOUAE0939-0940, 2: 408-599 mm; TOU-AE0943, $711 \mathrm{~mm}$; TOU-AE1160, 806 mm; TOU-AE1518-1521, 4: 510$664 \mathrm{~mm}$; TOU-AE1527-1531, 5: 413-652 mm; TOUAE1534-1538, 5: 334-689 mm; TOU-AE1544-1549, 6: 383-883 mm; TOU-AE1665-1669, 5: 457-669 mm; TOU-AE1674-1677, 4: 348-631 mm.

Gymnothorax reevesii: 9 specimens. ASIZP0056653, $650 \mathrm{~mm}$; NMMSTP00941, $698 \mathrm{~mm}$; TOU-AE0130, $432 \mathrm{~mm}$; TOU-AE0219, $534 \mathrm{~mm}$; TOUAE0581, 685 mm; TOU-AE0831-0833, 3: 457-592 mm; TOU-AE1369, $725 \mathrm{~mm}$.

\section{Diagnosis:}

Body length moderate (maximum size reaches 608 mm TL), smaller body depth (Figure 1). Dorsal fin moderately high; origin before the gill opening. Anus close to mid-body point. Jaw teeth caniniform and generally uni-serial, but bi-serial on anterior dentaries and maxillae. Body and fins light brown, with larger dark brown spots on body side in three rows at minimum, with only a few dark brown dots on the dorsal fin; paler jaws, rictus, and abdomen; anterior area of head lacks large dark spots. When alive, the irises of the eyes are yellow to orange and the body spots are dark reddish brown.
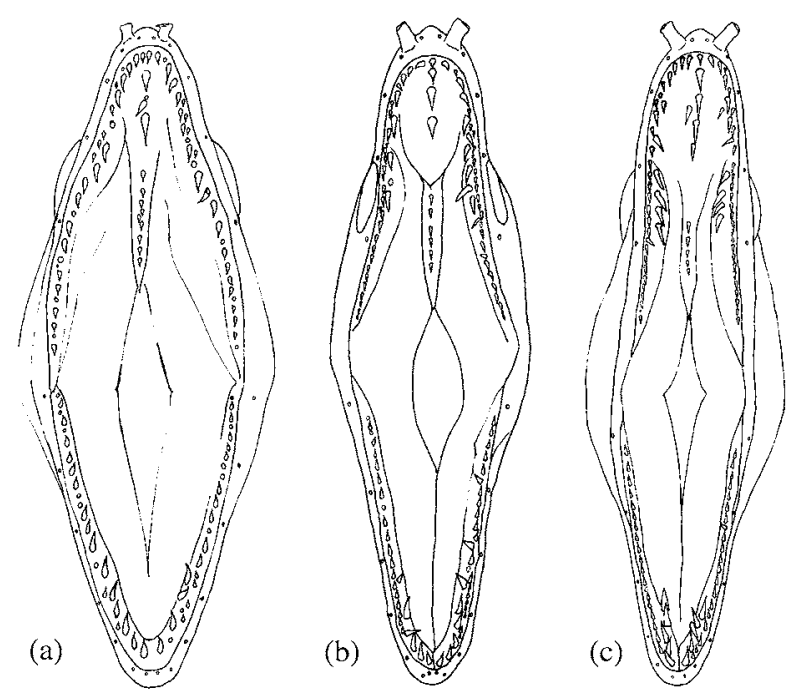

Fig. 2. Dentitions of type specimens of Gymnothorax shaoi: holotype, male; (a) ASIZP 0062978; paratypes, females; (b) ASIZP 0062980; (c) TOU-AE 0381. 


\section{Description:}

Data for holotype, followed in parentheses by the mean and range of data for the holotype and eight paratypes (exclude specimen TOU-AE 1797). The asterisk (*) indicates that data were affected by a missing tail-tip. Tail length $2.02(2.00 * ; 1.94 *-2.06)$; trunk length $2.70(2.67 ; 2.56-2.81)$; depth at anus 17.26 $(20.71 * ; 17.26-24.62)$; depth at gill opening 14.32 (17. $39 * ; 14.32-23.53)$; head length $7.46(7.77 * ; 7.35 *-8$. 26), all in TL. Predorsal length 1.58 (1.54; 1.45-1.76); upper jaw length $2.54(2.38 ; 2.19-2.54)$; lower jaw length 2.55 (2.40; 2.24-2.55); snout length 5.91 (5.70; 5.04-6.19); eye diameter 13.06 (11.71; 10.25-13.06); interorbital width 7.68 (7.72; 5.98-9.72), all in HL. Predorsal vertebrae $5(3.9 ; 3-5)$; pre-epipleural vertebrae 52 (49.9; 45-53); preanal vertebrae 57 (55.8; 53 $57)$; and total vertebrae $129(125.1 * ; 112 *-130)$. Lengths, proportions, vertebral counts and gonadal type of the holotype and eight paratypes of G. shaoi n. sp. are shown in Table 1.

Dorsal fin moderately high, origin before the gill opening and above the 3-5th vertebra. The depth of anal fin low, origin just behind anus and below 53-57th vertebra. Gill opening on mid-body, and its length nearly equal to eye diameter.

Anterior nostrils were tubular on each side of snout tip. Tips of anterior nostrils were lower and with darkish flounced rims. Posterior nostrils were short tubular over each front edge of eye with darkish raised funneled rims.

Head pores distinct. Supraorbital canal with three pores, one of them situated anteroventrally to anterior nostril. Infraorbital canal with four pores. Mandibular canal with six to seven pores. Two branchial pores situated near the mid-point area of origin of dorsal fin to gill opening.

Mouth in terminal position and closing completely. Caniniform teeth in jaws, pointed and slightly retrorse

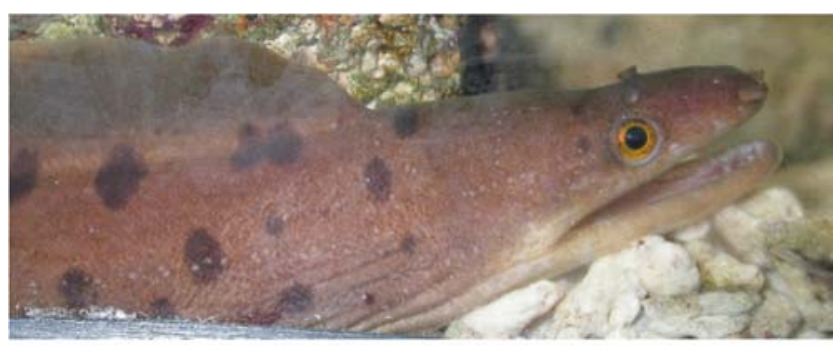

(a)

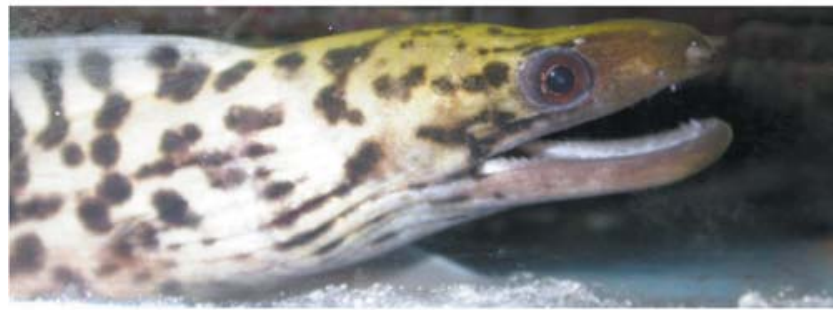

(b)

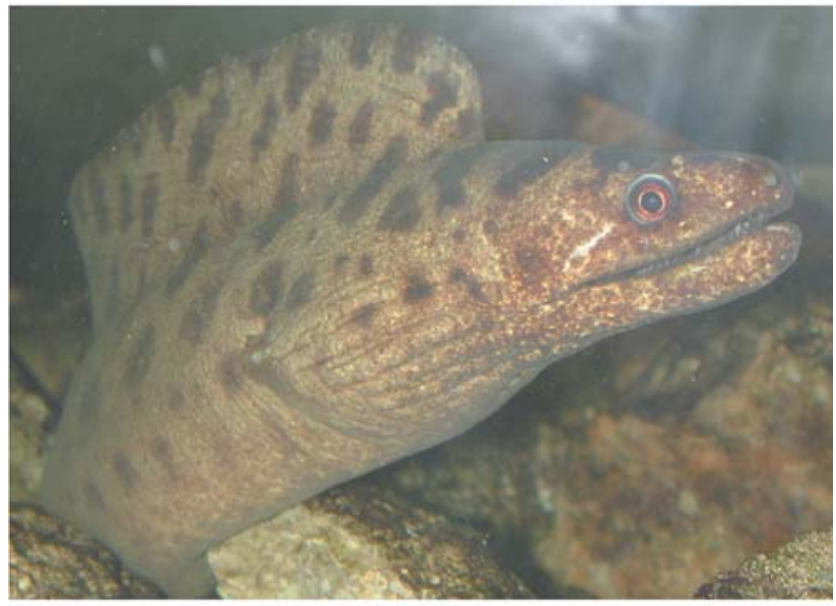

(c)

Fig. 3. Comparisons of head characters of Gymnothorax shaoi (a: paratype, TOU-AE 0381) with two similar species, G. fimbriatus (b) and $G$. reevesii $(\mathrm{c})$.

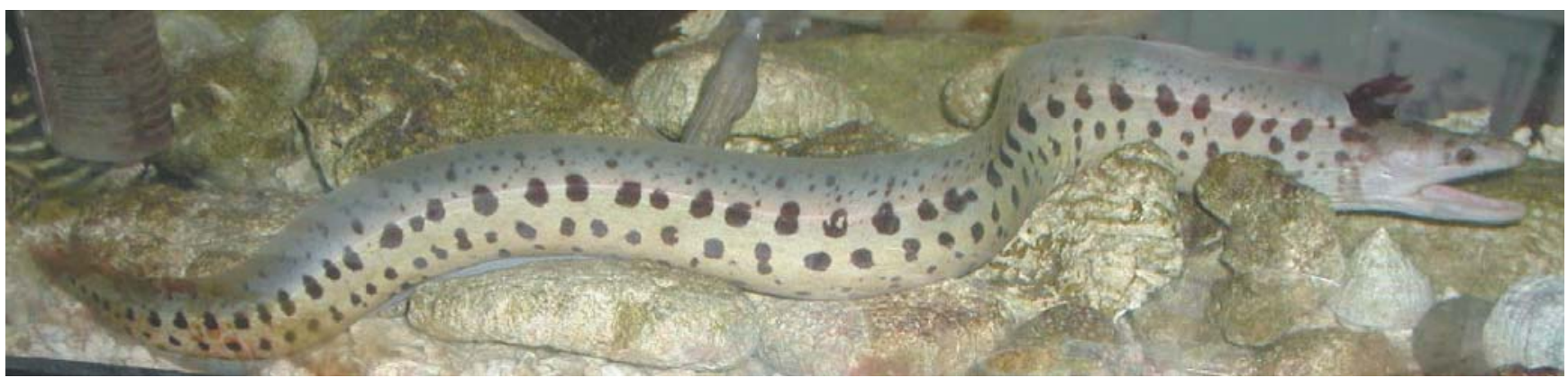

Fig. 4. The paratype (TOU-AE1797, $492 \mathrm{~mm}$ TL, from Changbin) of Gymnothorax shaoi reared in our laboratory exhibited the paler ground color at night. 
(Figure 2). Teeth of peripheral series of premaxillary plate 14-23 (these counts include shed teeth); several small teeth found in some spaces between lateral teeth of peripheral series of premaxillary plate. Mesial series of premaxillary plate with 3-4 teeth, with posterior larger. Vomerine teeth small, in a straight series and 5-9 in number. Maxillary teeth in double rows, 17-18 canines on outer row of each side and 3-4 longer inner canines in anterior maxilla. Mandibular teeth in double rows, 4-5 larger canines on inner row of anterior dentary and 19-23 canines on outer row of dentary. As in the peripheral series of premaxillary teeth, several small teeth found in the space between larger teeth on anterior dentary near symphysis.

Body color in formalin or alcohol grey brown. Dark brown spots on body side mainly in three rows, one row along dorsal fin base, one row along lateralline, and one row along anal fin base. Some small dark brown dots were scattered on dorsal fin or body side. Paler rictus and abdomen. No obviously dark spots on jaws, inner mouth, chin and anal fin. Body color when alive similar to color in preservative, but the brown ground color a little reddish at day (Figure 3a) or more pale at night (Figure 4). When alive, G. shaoi has eyes with yellow to orange irises and body with dark reddish brown spots.

\section{Distribution:}

From southeastern Taiwan. Off shore of Chengkung $\left(23.130^{\circ} \mathrm{N}, 121.414^{\circ} \mathrm{E}\right)$ to Changbin (23. $\left.311^{\circ} \mathrm{N}, 121.453^{\circ} \mathrm{E}\right)$, Taitung County, Taiwan.

\section{Remarks:}

The new muraenid Gymnothorax shaoi is clearly distinct from the most similar species G. fimbriatus (Bennett) [1] (Figure 3b) in the character combinations of brown body color, dark brown spots on body side in at least three rows, spots on posterior dorsal and caudal fin that do not form oblique streaks; paler rictus, jaws and inner mouth; fins without pale margins; no bend in lower jaw; fewer total vertebrae (mean total vertebrae 128 vs. 143 [6]); smaller maximum size (reaches 608 vs. $883 \mathrm{~mm} \mathrm{TL}$ ) (Table 2). G. shaoi has eyes with yellow to orange irises, body with dark reddish brown spots, and lack yellow mucus character on the top of head when alive. G. fimbriatus has whitish to yellowish body color and dense yellow mucus on head, blackish spots on body, blackish mouth corners, dark jaws, blackish skin in inner mouth, remarkable whitish margin on the anal and caudal fins, and dark reddish eye irises when alive.

G. shaoi also differs from another similar species G. reevesii (Richardson) [12] (Figure 3c) in the characters of smaller body depth (DGO. 4.3-7.0 vs 9.1-10.1\% of TL.) [7, 9], longer snout length (16.2-19.9 vs 13.5$16.1 \%$ of HL.), absence of pale posterior nostrils, only a few dark brown dots on the dorsal fin, and absence of blackish margins on fins. G. reevesii has numerous large obscure dark brownish spots in 3-5 rows along the body side, many small brownish dots speckled about the body, posterior caudal fin with oblique comb-like dark brown bands, fins with a dark margin. G. shaoi has more inner maxillary (3-4 vs. 0$)$ and inner dentary (4-5

Table 1. Lengths, proportions, vertebral counts and gonadal type of the holotype and eight paratypes of Gymnothorax shaoi n. sp.

\begin{tabular}{|c|c|c|c|c|c|c|c|c|c|c|c|c|c|c|c|c|c|c|}
\hline & \multirow{2}{*}{\multicolumn{2}{|c|}{$\frac{\text { Holotype }}{\text { ASIZP0062978 }}$}} & \multicolumn{16}{|c|}{ Paratypes } \\
\hline & & & \multicolumn{2}{|c|}{ ASIZP0062979 } & \multicolumn{2}{|c|}{ ASIZP0062980 } & \multicolumn{2}{|c|}{ TOU-AE0370 } & \multicolumn{2}{|c|}{ TOU-AE0371 } & \multicolumn{2}{|c|}{ TOU-AE0372 } & \multicolumn{2}{|c|}{ TOU-AE0373 } & \multicolumn{2}{|c|}{ TOU-AE0375 } & \multicolumn{2}{|c|}{ TOU-AE0381 } \\
\hline & $(\mathrm{mm})$ & $(\%)$ & $(\mathrm{mm})$ & $(\%)$ & $(\mathrm{mm})$ & $(\%)$ & $(\mathrm{mm})$ & $(\%)$ & $(\mathrm{mm})$ & $(\%)$ & $(\mathrm{mm})$ & $(\%)$ & $(\mathrm{mm})$ & $(\%)$ & $(\mathrm{mm})$ & $(\%)$ & $(\mathrm{mm})$ & $(\%)$ \\
\hline Total length & 567 & & 457 & & 401 & & 458 & & 416 & & $405^{*}$ & & $398^{*}$ & & 608 & & 379 & \\
\hline \multicolumn{19}{|l|}{$\%$ of total length } \\
\hline Tail length & 281 & 49.6 & 236 & 51.6 & 203 & 50.6 & 224 & 48.9 & 213 & 51.2 & 201 & $49.6^{*}$ & 193 & $48.5^{*}$ & 303 & 49.8 & 191 & 50.4 \\
\hline Trunk length & 210 & 37.0 & 169 & 37.0 & 148 & 36.9 & 179 & 39.1 & 157 & 37.7 & 153 & $37.8^{*}$ & 152 & $38.2^{*}$ & 233 & 38.3 & 135 & 35.6 \\
\hline Body depth at anus & 32.9 & 5.8 & 22.0 & 4.8 & 16.3 & 4.1 & 23.2 & 5.1 & 23.0 & 5.5 & 22.3 & $5.5^{*}$ & 20.2 & $5.1^{*}$ & 25.4 & 4.2 & 15.7 & 4.1 \\
\hline Body depth at gill openin & 39.6 & 7.0 & 28.0 & 6.1 & 23.5 & 5.9 & 26.0 & 5.7 & 24.3 & 5.8 & 23.0 & $5.7^{*}$ & 23.8 & $6.0^{*}$ & 37.2 & 6.1 & 16.1 & 4.3 \\
\hline Head length & 76.0 & 13.4 & 58.0 & 12.7 & 52.2 & 13.0 & 55.4 & 12.1 & 51.6 & 12.4 & 55.1 & $13.6^{*}$ & 51.4 & $12.9^{*}$ & 78.0 & 12.8 & 49.3 & 13.0 \\
\hline \multicolumn{19}{|l|}{$\%$ of head length } \\
\hline Predorsal length & 48.3 & 63.5 & 38.1 & 65.7 & 36.0 & 69.0 & 37.4 & 67.5 & 35.4 & 68.6 & 31.3 & 56.8 & 34.6 & 67.4 & 49.7 & 63.7 & 32.0 & 64.9 \\
\hline Upper Jaw length & 29.9 & 39.3 & 26.4 & 45.6 & 20.6 & 39.4 & 24.1 & 43.4 & 23.6 & 45.7 & 23.1 & 41.8 & 21.0 & 40.8 & 31.5 & 40.4 & 21.0 & 42.6 \\
\hline Lower Jaw length & 29.8 & 39.3 & 25.9 & 44.7 & 21.2 & 40.7 & 23.5 & 42.4 & 21.7 & 42.1 & 24.2 & 43.9 & 20.3 & 39.5 & 32.0 & 41.0 & 21.1 & 42.8 \\
\hline Snout length & 12.9 & 16.9 & 11.5 & 19.8 & 8.4 & 16.2 & 9.3 & 16.8 & 9.8 & 19.0 & 9.6 & 17.3 & 8.7 & 16.9 & 13.6 & 17.5 & 8.9 & 18.0 \\
\hline Eye diameter & 5.8 & 7.7 & 5.2 & 9.0 & 5.1 & 9.8 & 4.7 & 8.5 & 4.7 & 9.1 & 4.3 & 7.9 & 4.7 & 9.1 & 6.1 & 7.8 & 4.2 & 8.5 \\
\hline Interorbital width & 9.9 & 13.0 & 9.7 & 16.7 & 6.5 & 12.4 & 5.7 & 10.3 & 7.4 & 14.4 & 7.8 & 14.1 & 5.5 & 10.7 & 10.0 & 12.8 & 7.2 & 14.6 \\
\hline Predorsal vertebrae & 5 & & 4 & & 4 & & 4 & & 4 & & 3 & & 4 & & 3 & & 4 & \\
\hline Preanal vertebrae & 57 & & 56 & & 56 & & 57 & & 53 & & 53 & & 56 & & 57 & & 57 & \\
\hline Total vertebrae & 129 & & 130 & & 128 & & 128 & & 125 & & $112 *$ & & $118^{*}$ & & 129 & & 127 & \\
\hline Gonadal type & testis & & ovary & & ovary & & testis & & testis & & ovary & & testis & & testis & & ovary & \\
\hline
\end{tabular}

Note: *Tip of tail missing 
Table 2. Comparisons of proportions, counts, coloration, and other characters among Gymnothorax fimbriatus, $G$. reevesii and $G$. shaoi n. sp.

\begin{tabular}{|c|c|c|c|}
\hline & G. fimbriatus & G. reevesii & G. shaoi \\
\hline \multicolumn{4}{|l|}{$\%$ of total length } \\
\hline Body depth at gill opening & $5.9-8.1$ & $9.1-10.1$ & $4.3-7.0$ \\
\hline \multicolumn{4}{|l|}{$\%$ of head length } \\
\hline Snout length & $14.9-18.9$ & $13.5-16.1$ & $16.2-19.9$ \\
\hline Upper Jaw length & $34.5-57.1$ & $38.7-45.1$ & $39.3-45.8$ \\
\hline Lower Jaw length & $33.8-58.1$ & $37.1-43.4$ & $39.3-44.7$ \\
\hline \multicolumn{4}{|l|}{ Counts } \\
\hline Total vertebrae (mean) & 131-133(132); 143* & $125-128(127)$ & $125-130(128)$ \\
\hline Inner maxillary teeth & $1-4$ & 0 & $3-4$ \\
\hline Inner dentary teeth & $2-4$ & 0 & $4-5$ \\
\hline \multicolumn{4}{|l|}{ Coloration } \\
\hline Body color & Whitish to yellowish & Yellowish brown to brownish & Gray to brownish \\
\hline Body spots & Blackish & Dark brownish & Reddish brown \\
\hline Irises of eyes & Dark reddish & Dark reddish & Yellowish to orangey \\
\hline Jaws & Darkish & Brownish & Pale \\
\hline Margins of fins & Whitish & Dark brownish & Brownish \\
\hline Posterior nostrils & Brownish & Pale & Darkish \\
\hline Rictus of mouth & Blackish & Brownish & Pale \\
\hline Skin of inner mouth & Blackish & Brownish & Pale \\
\hline Top of head yellowish & Yes & No & No \\
\hline Bend in lower jaw & Yes & No & No \\
\hline Maximum total length & $883 \mathrm{~mm}$ & $698 \mathrm{~mm}$ & $608 \mathrm{~mm}$ \\
\hline
\end{tabular}

Note: *Data from [6]

vs. 0) teeth than $G$. reevesii.

Böhlke and Smith [6] reviewed the type catalogue of Indo-Pacific Muraenidae. They remarked on Bleeker's specimen (BMNH 1867.11.28.238) of "Gymnothorax bullatus" [2] (misidentified, not Muraena bullata Richardson [13]) as the holotype of "Muraena microspila Günther[10]". Color patterns of the specimen depicted in Bleeker's Atlas [2] was somewhat similar to our $G$. shaoi. However, the specimen had darkish fin margins and its dentition was closer to the diagnosis of $G$. reevesii which was reviewed in Chen et al. [7]. Böhlke et al. [4] cited the drawing of "Gymnothorax bullatus" from Bleeker Atlas [2] and renamed it as G. reevesii. Böhlke and Smith [6] also remarked that the specimen (BMNH 1867.11.28.238) was G. reevesii, and considered "Muraena microspila" as the junior synonym of $G$. reevesii.

Key to Gymnothorax species which have numerous dark spots speckling on gray to brownish body:

1a. Margin of fins yellowish G. buroensis

1b. Margin of fins not yellowish 2 2a. Body with black round spots; spots are more dense and numerous on head G. favagineus

2b. Body with dark spots; spots are not dense and numerous on head 3

3a. Upper region of head yellowish ...... G. fimbriatus

3b. Upper region of head not yellowish 4

4a. Dark reddish irises, caudal fin with darkish margin

G. reevesii

4b. Yellowish to orangey irises, caudal fin without darkish margin G. shaoi

\section{Etymology:}

We name this species Gymnothorax shaoi in honor of Dr. Kwang-Tsao Shao, who has contributed greatly to establish the Taiwanese fish database as well as supervise and support for our muraenid studies.

\section{ACKNOWLEDGEMENTS}

We wish to thank Dr. Kwang-Tsao Shao, Acting Director of the Research Center for Biodiversity, 
Academia Sinica; and Dr. Ching-Fong Chang in our University, for their valuable advice and support throughout the studies. We give particular thanks to Dr. Daniel J. Sheehy and Dr. Susan Vik. for revising the manuscript. We are very grateful to Mr. Wung-Jyh Yang and Captain Jiunn-Shiun Chiou who collected the type and relative specimens. Mr. Wei-Jen Chen, Mr. Yen-Chieh Tseng, Mr. Chao-Sen Yang and Miss Shih-Ying Tien measured the type specimens and reared the comparative morays in our aquaria.

These studies were originally supported by Fisheries Agency, Council of Agriculture grants "92AS-9.1.1FA-F1(8); 93AS-9.1.1-FA-F2(1-4); 94AS-9.4.1-FA-F1 (3-4)" to Hong-Ming Chen. This study was also partially supported by the Center for Marine Bioscience and Biotechnology in National Taiwan Ocean University.

\section{REFERENCES}

1. Bennett, E.T., "Observations on a Collection of Fishes from the Mauritius, Presented by Mr. Telfair, with Characters of New Genera and Species," Proceedings of the Zoological Society of London, Vol. 1, pp. 165-169 (1832).

2. Bleeker, P., "Murènes, Synbranches, Leptocéphales," Atlas Ichthyologique des Indes Orientales Néêrlandaises, Publie Sous les Auspices du Gouvernement Colonial Néêrladaises. Tome IV, Amsterdam, pp. 1-150, pls. 144193 (1864).

3. Böhlke, E.B., "Vertebral Formulae of Type Specimens of Eels (Pisces: Anguilliformes)," Proceedings of the Academy of Natural Sciences of Philadelphia, Vol. 134, pp. 31-49 (1982).

4. Böhlke, E.B., McCosker, J.E., and Smith, D.G., "Muraenidae-Morays," in K.E. Carpenter and V.H. Niem (eds.), FAO Species Identification Guide for Fishery Purposes. The Living Marine Resources of the Western Central Pacific, Rome: FAO of the United Nations, Vol. 3, pp. 1643-1657 (1999).
5. Böhlke, E.B. and Randall, J.E., "A Review of the Moray Eels (Anguillifromes: Muraenidae) of the Hawaiian Island, with Descriptions of Two New Species," Proceedings of the Academy of Natural Sciences of Philadelphia, Vol. 150, pp. 203-278 (2000).

6. Böhlke, E.B. and Smith, D.G., "Type Catalogue of IndoPacific Muraenidae," Proceedings of the Academy of Natural Sciences of Philadelphia, Vol. 152, pp. 89-172 (2002).

7. Chen, H.M., Shao, K.T., and Chen, C.T., "A Review of the Muraenid Eels (Family Muraenidae) from Taiwan with Descriptions of Twelve New Records," Zoological Studies, Vol. 33, No. 1, pp. 44-64 (1994).

8. Chen, H.M., Shao, K.T., and Chen, C.T., "A New Moray Eel, Gymnothorax niphostigmus, (Anguilliformes: Muraenidae ) from Northern and Eastern Taiwan," Zoological Studies, Vol. 35, No. 1, pp. 20-24 (1996).

9. Chen, H.M., Chen, C.T., and Shao, K.T., "Systematic Studies on the Muraenid Fishes (Muraenidae) from the Waters Around Taiwan," Ph. D. Thesis, Department of Fishery Science, National Taiwan Ocean University, Keelung, Taiwan, pp. 1-257 (1997) (in Chinese).

10. Günther, A., Catalogue of the Fishes in the British Museum, British Museum, London, Vol. 8, pp. 1-549 (1870).

11. Hatooka, K., "Sexual Dimorphism Found in Teeth of Three Species of Moray Eels," Japanese Journal of Ichthyology, Vol. 32, No. 4, pp. 379-386 (1986).

12. Richardson, J., "Ichthyology," In Hinds, R.B. (eds.), The Zoology of the Voyage of H.M.S. Sulphur, Under the Command of Captain Sir Edward Belcher, etc., During the Years 1836-42, Smith, Elder and Co., London, pp. 51-150, pls. 35-64 (1844-1845).

13. Richardson, J., Ichthyology of the Voyage of H.M.S Erebus and Terror, under the Command of Captain Sir JC Ross, etc., During the Years 1839-43, London, Vol. 2, pp. 1-139 (1844-1848). 